\title{
Gas Sensor Design Using a Fabry-Perot Interferometer With Long Cavity Length As a Modulator
}

\author{
Everardo Vargas-Rodríguez and Harvey N. Rutt. \\ Optoelectronics Research Centre, University of Southampton, \\ Bldg. B47, Highfield Campus, SO17 IBJ, Southampton, UK. \\ Tel: $+44(0)$ 2380594530, fax: +44 (0) 2380593149 \\ email:evr@orc.soton.ac.uk and hnr@ecs.soton.ac.uk
}

\begin{abstract}
A gas sensor based on correlation spectroscopy using a FPI with long cavity length $(>500 \mu \mathrm{m})$ as a modulator is presented. Eventually the FPI and the optical detector will be integrated within a MEMS structure.

(C2005 Optical Society of America

OCIS codes: (220.4830) Optical systems design; (120.4640) Optical instruments; (120.4570) Optical design of instruments
\end{abstract}

\section{Introduction}

MEMS technology is evolving rapidly and currently miniaturization and integration of Fabry-Perot Interferometers (FPI) is possible. Several publications on the design of tuneable MEMS-FPI can be found in the literature, for instance see [1-3]. One popular application of these MEMS-FPIs is gas sensing since the FPI and the optical detector can be integrated within the same MEMS structure [4,5], reducing considerably the sensor size, cost and its power consumption. Here, we present a gas sensor design which uses a FPI as a modulator which eventually can be integrated within a MEMS structure.

\section{Gas sensor using a FPI with long cavity length}

In this paper a gas sensor design based on correlation spectroscopy using a FPI as a modulator is presented. In this design the spectral fringes produced by the FPI are matched with the absorption vibrational-rotational lines of the target molecule. To induce modulation the FPI fringes are shifted along the frequency axis changing the total light transmission [6], by modulating the FPI cavity length. This design is suitable for detecting molecules with very well defined absorption lines which are characteristic in most linear and diatomic molecules such as $\mathrm{CO}$ and $\mathrm{CO}_{2}$. Here, to match the spectral FPI fringes with the rotational absorption lines we need a FPI with long cavity length $(d)$, generally above $500 \mu \mathrm{m}$ depending on the target gas. This is much longer than the cavity length of most of the current MEMS-FPI which is generally $d \leq 40 \mu \mathrm{m}$ [1-5]. It is shown that gas sensors using a FPI with long cavity length have very high selectivity to the target gas, reducing errors due to cross sensitivity. Moreover, it is shown that FPI mirrors with low reflectivity ( $\leq 45 \%$ ) and $\sim 1 \mathrm{~mm}$ diameter are required for this application, relaxing considerably the future MEMS fabrication. Currently we have finished the construction of a proof of principle bench top prototype using bulk optics components, which allow us to test the performance of the sensor design for different target gases. Simulation and preliminary experimental results for a $\mathrm{CO}_{2}$, a $\mathrm{CO}$ and a $\mathrm{CH}_{4}$ gas sensors will be presented.

\section{References}

[1] F. Grasdepot, H. Alause, W. Knap, J. P. Malzac and J. Suski, "Domestic gas sensor with micromachined optical tunable filter," Sensor and Actuators B 35-36, 377-380 (1996).

[2] C. Calaza, L. Fonseca, M. Moreno, S. Marco, C. Cané and I. Gracia, "A surface micromachining process for the development of a mediuminfrared tuneable Fabry-Perot interferometer," Sensor and Actuators A 113, 39-47 (2004).

[3] J. H. Jerman and S. R. Mallinson, "A Miniature Fabry-Perot Interferometer Fabricated Using Silicon Micromachining Techniques," in THO215-4 IEEE, pp 16-18 (1998).

[4] H. Carlson, "CARBOCAP - new carbon dioxide sensor electrically tuneable interferometer for infrared gas analysis," Sensor Review 17, 304306 (1997).

[5] M. Noro, K. Suzuki, N. Kishi, H. Hara, T. Watanabe and H. Iwaoka, "CO2/H2O gas sensor with a MEMS Fabry-Perot filter," in 2002 IEEE/LEOS International Conference on Optical MEMS, (2002).

[6] J. P. Dakin, "Review of Fibre Optic Gas Sensors," The Plessey Company PLC, (1988). 